\title{
Commercialization Type of Research Results in Technology Transfer: a Review of Determination Strategies
}

\author{
Susirani Kusumaputri, Yovita Isnasari \\ Indonesian Institute of Science \\ Center for Innovation \\ Bogor, West Java, Indonesia \\ susirani.kusumaputri@yahoo.com, yovita.isnasari@lipi.go.id
}

\begin{abstract}
Technology transfer is a downstream form of research and development result. Research result can be transferred in many kinds of commercialization type, including technology licensing and established a new company based on technology (Start-up Company). The success of technology transfer is determined by the selection of research result and commercialization types. Centre for Innovation as a division which has duties and function as the Technology Transfer Office (TTO) has already conducted these two types. This paper aims to analyze the various form of existing research result in LIPI and appropriate commercialization type. The method used in this paper is a qualitative descriptive, through information searching related to the topics from written source and interviews. In this paper, we found that research result could be licensed which is the result is a process and require further processing to apply it. Whereas research result to be transferred to the new company is the result in product form and can be implemented directly.
\end{abstract}

Keywords - transfer technology, technology transfer office, start-up company

\section{INTRODUCTION}

The growth of competition forces institutions to look for solutions in order to gain competitiveness. Innovation has been nominated as the driver of the economic growth. Innovation should not only be considered as "invention" or "R\&D", but also as a systematic process [1]. A technological innovation system is a set of networks of actors and institutions that jointly interact in a specific technological field and contribute to the generation, diffusion and utilization of variants of a new technology and/or a new product [2].

Technology transfer has been characterized as adoption of innovation [3]. The transfer of technology has become a very effective way to disseminate innovation. Technology transfer has been emphasized as a challenging task and important driver in innovation and the creation of sustainable growth. The transfer of technology itself is the transfer of the ability to utilize and master of science and technology. The transfer of technology is an alternative to competitive for a work unit to search not only for the exploration of internal resources to take advantage of intellectual property as well as the results of research and development activities, but also for external partners to getting an increase in new technology to make it a new business opportunity in the form of start-up company [4].
The outputs of the technology transfer mechanisms range from intangible to tangible outcomes. Patenting, Licensing, and start-up are the most frequently discussed and relevant technology transfer methods in the literature, while a few studies emphasized the importance of other methods such as consulting, training, and exchange programs [5].

Development of technology transfer carried out at Indonesian Institutes of Sciences (LIPI) referring to Government Regulation No. 20 of 2005 concerning Intellectual Property Technology Transfer [6]. The above rule is reinforced by Indonesian Presidential Regulation Number 27 of 2013 on the Development of Entrepreneurial Incubator to improve national competitiveness [7]. The purpose of these regulations is to spread knowledge and technology and increase science and diffusion capacity of communities.

There are numerous studies identified with exploration organizations or college to accomodate innovation exchange, for the most part centered around establishments that encourage commercialization, for example, Technology Transfer Offices (TTOs) and components that encourage commercialization, for example, licenses, authorizing, and spinoffs or new companies [8]. The TTO facilitates the transfers of commercial knowledge through licensing innovation from research results [9]. The process of such transfer is considered to be something of a black box [8].

The commercialisation of academic knowledge on technology transfer, involving the patenting and licensing of inventions as well entrepreneurship, has attracted major attention both within the academic literature and the policy community. Commercialisation is considered a prime example for generating academic impact because it constitutes immediate, measurable market acceptance for outputs of academic research [10].

One of the most common problems in technology transfer is the definition and pathway of technology that is being transferred and commercialized. Among the many categories of transfer object, one enduring focus has been on commercializable products. To what extent do the transfer objects achieve commercialization and what is their rate of commercialization success [11]. There are multiple pathways that can be used to commercialize research results. Center for 
Innovation LIPI as TTO aim to answer and see that intellectual property as well as the results of research and development activities could be harnessed into a knowledge-based business and or economic value of technology that has a significant impact on the growth of business starters. The TTO evaluates its potential of commercialization, and decides patenting strategies. The TTO is in a stronger negotiation position as it seeks to market and commercialize the intellectual property.

Research result commercialization broadly divided into three models, that are an assignment of IP rights, licensing to the industry partner, and the creation of a new company based on the licensed technology developed in the research institution [12]. Commercialization of the technology by the Center for Innovation can be broadly classified into two models, the Technology Licensing and Start-up Company.

In other countries, licensing and the formation of new companies (start-ups) have been commonplace over the last few years. It can take months and sometimes years to locate a potential licensee, depending on the attractiveness of the invention and the size and intensity of the market. The number of active licenses (contracts whose licenses are continuing) in Japan in 2010 was 5,770. While there were 33,523 active licenses in the United States in 2009 [12]. Before a license can be granted to a start-up, the invention is marketed to other potential licensees who may have an interest in commercializing it.

Large companies are the recipients of transferred technologies. In the United States, universities transfer approximately $15 \%$ of their technology to startup companies and about half to small and medium-sized enterprises (SMEs) [13]. However, it is not the same when it comes to Japan as only a small amount of licenses (5\%) goes to start-up companies [12]. From a technology transfer perspective, the startup company with an entrepreneur committed to developing a particular technology may be the best licensee, but the startup company must offer a viable plan to commercialize an invention in order to receive a license [12].

Implementation of technology transfer raises questions: what types of commercialization of research results should the institution support and encourage. This is consistent with the survey done by [14] about major outputs mostly recognized by the TTO. It also surveyed how different stakeholders defined the outcomes of technology transfer. The study found that while all parties concerned consider licenses as an important outcome of technology transfer, various types of stakeholders possess different opinions on royalties, informal knowledge transfer, and product development.

Studies that explores the strategies in determining commercialization model in Indonesia is lacking, especially to that pertaining to LIPI. Hence, this paper will discuss the types of commercialization in LIPI in the technology transfer of research results. The rest of this paper is structured as follows. Section 2 provides a review of commercialization models. Section 3 briefly describes the research method. Section 4 presents the results and its discussion. Section 5 then concludes.

\section{MODELS OF COMMERCIALIZATION IN ORDER TO TECHNOLOGY TRANSFER}

Technology transfer is the final process in research activities. Technology transfer is understood as an attempt to disseminate technology derived from research institutions as the owner of the technology or moves from creator to user. In the Indonesian Legal System, technology transfer appears the Government Regulation No. 20 Year 2005, which state that "Technology transfer is the transfer of the ability to utilize and master of science and technology between institution, agencies or people, both located within or outside the territory of the country, into the country or otherwise" [6]. The scope of technology transfer in Indonesian Legal System is limited by the lack of authority of research institutions to commercialize research results. So in technology transfer will be in bridging the Technology Transfer Office (TTO)

TTO have been included in the Research Institution organizational structure, to facilitate the passage of research result from research institution to industry (business) [11]. TTO can be defined as a bridge between technology supplier and technology receiver [13]. The Organization for Economic Cooperation and Development (OECD) define TTO as part of an organization which assist the identification, protection, exploitation and defence of an intellectual property [12]. Each TTO has their model of technology transfer that is adjusted to the character of research result and markets need.

There are many common models of technology transfer such as "the appropriated model, the dissemination model, the knowledge utilization model, the contextual collaboration model, the material transfer model, the design transfer model, and the capacity transfer model" [15]. Even though, technology transfer not always done with the commercialization purpose, but also done in models of technology dissemination. Research result commercialization broadly divided into three models, that are an assignment of IP rights, licensing to the industry partner, and the creation of a new company based on the licensed technology developed in the research institution [13].

Research institution often makes some cooperation with industry, including licensing of intellectual property, performing contract-based research and undertaking government-funded research projects jointly with firms. In addition, research institutes also encourage the creation of new companies based on technology that has been developed [16]. Nonetheless, the notion of technology transfer, the form of technology transfer transactions not only in the scope of the contract or agreement for the transfer of technology but also involves the communication of relevant knowledge by the transferor (the owner of the technology) to recipients [14].

\section{A. Technology Licensing}

Licensing is a way through which an owner exploit their Intellectual Property assets. Technology licensing just does when one of the parties owns valuable intangible assets [17]. Technology licensing is a form of technology transfer of research result that is ready for adoption industry. Technology as the research result will generally be licensed been protected by Intellectual Property through patent, copyright, and plant variety protection. Licensing involves the granting of the right 
to make, use or sell a proprietary product, process, or service by a firm owning the rights to the intellectual property (licensor) to another firm (licensee) in return for some payment [18]. Although technology licensing is also possible to license the technology that does not yet requested IP protection [19]. Technology licensing that has no protection IP, in general, is a process technology or a particular method.

The process of technology licensing is broadly divided into two parties. A party who have IP will become a Licensor or party who give IP to another party. While the other party who is receiving the technology known as Licensee. Licensor and Licensee in making technology licenses will be tied up in the Licensing Agreement were agreed. Licensing Agreement contains provisions regarding the nature of rights granted to the licensee, the compensation structure, and the duration of the agreement [20].

The process of technology license will also take into consideration the quality of the transferred technology, the quality of these technologies will affect the nominal which will be paid by the Licensee to the Licensor. Arrow [21] pointed out that a potential licensee would naturally wish to verify the quality of the invention before paying for it. Also, one consideration in choosing the company that will receive technology (Licensee) is the financial condition and ability to adopt these technologies [22].

\section{B. New Company}

While many research organizations focus on putting technologies into spin-off companies, for the vast majority of IP created within research laboratories, the most suitable commercialization path is licensing the IP to a corporation that is already a global leader in the target industry. Technologies of this kind tend to have incremental benefits over competitive offerings available on the market and often need to be presented in combination with complementary technologies to provide utility to the target customer. In addition, Australian Centre for Innovation suggests that licensing is most likely to be the preferred route for mature industries and technologies [23]. As for the United States, in 2010, 651 new companies were formed upon research from 200 local universities and by the end of 2010, 3657 start-ups were still operating [24].

\section{METHODS}

The main focus of this paper is to discuss the types of commercialization in LIPI in the technology transfer of research results. To fulfil this objective, a narrative review is done. The authors collect and synthesize literatures consisting of reports, policy documents, journal articles, and unpublished sources.

The journal articles were browsed and selected based on relevance with the topic with keywords such as technology transfer, technology licensing, start-up company, and intellectual property. While the other materials were sourced mainly from the Center for Innovation of LIPI, government and private institutions, and other online sources.

\section{RESULTS AND DISCUSSION}

\section{A. Technology Transfer in LIPI}

The technology transfer process has been studied in various parts of the world, in one literature explained that there are six stages in the process of technology transfer, namely "technology innovation, technology confirmation, targeting technology consumers, technology marketing, technology application, technology evaluation" [25].

Technology commercialization is a more specific effort putting new invention and discovery into the market. There is a widely recognized commercialization process of inventions from research institutions to industry. Scientific or Technological Invention is first disclosed, and a patent application is filed. The patent or disclosure would be then licensed to an established company pursuing a financial benefit. A start-up firm by inventors or a third party is also another widely used commercialization method. The licensing is a necessary form to be used especially when an invention is considered for commercial purposes. While licensing means a specific legal contract and activity between a licensee and a licensor, the licensing often includes commercialization process starting with a disclosure and is used instead of commercialization.

LIPI work unit in the duties and function in conducting technology transfer is the Center for Innovation LIPI. Center for Innovation LIPI acts as an intermediary institution that plays a role in bridging between research institutions to community or industry. As an intermediary institution, Center for Innovation LIPI also plays a role in making technology incubation. This technology incubation serves to prepare the technology derived from the research laboratory to be better prepared to apply. Despite that, not all technologies have to pass through the incubation process. This is influenced by the level of technological readiness and the type of technology to be commercialized (Fig.1).

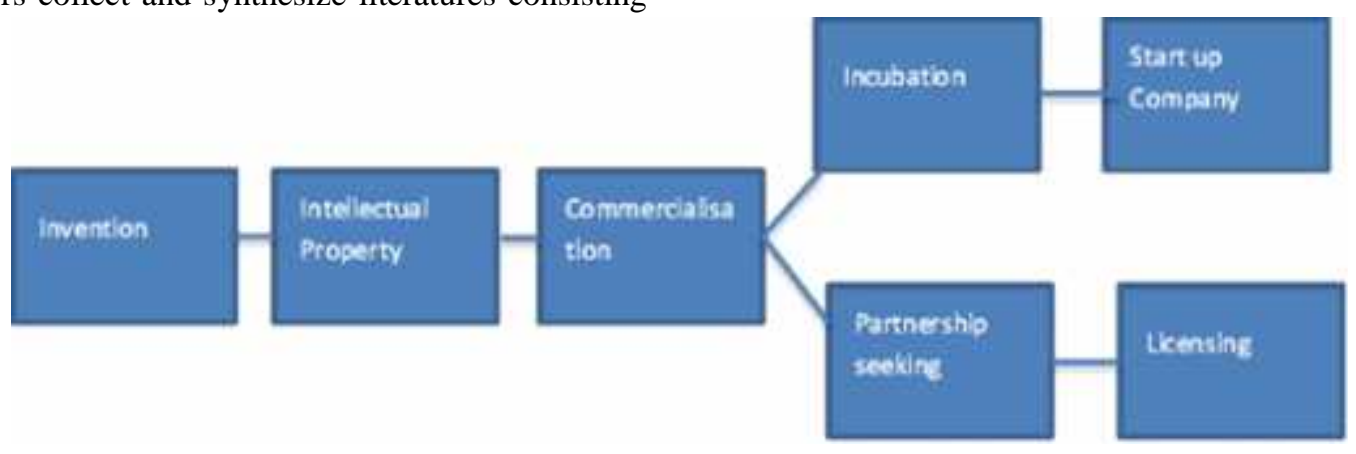

Fig. 1. Outline of Technology Transfer Process in LIPI. 
Commercialization of the technology by the Center for Innovation can be broadly classified into two models, the Technology Licensing and Start-up Company. Technology transfer by Center for Innovation LIPI conducted by specialized fields that deal with incubation and technology transfer through cooperation with the private sector. Not only regarding exploring cooperation but also conduct a feasibility study to assess the feasibility of a technology before it is applied to the industry. These are not mutually exclusive, and can be and usually are combined.

It is possible for a patent to be exploited by its own holder. However, the most common pathway of commercializing a patent is through licensing [26]. However, sometimes, the assignment of a patent can be a pathway to commercialization that not just warrants consideration, but in fact, depending on the occasion, may be the most desirable or even necessary pathway.

While the technology incubator program is intended to provide services for inventors and / or innovator both internal LIPI and from the public, business and new technology-based innovation in Indonesia. LIPI technology incubator is an intermediary institution that carries out the process of coaching, mentoring and development of the participant's incubation (tenant). LIPI technology incubator strives to create and develop new businesses that have economic value and high competitiveness by utilizing science and technology. The program aims to give birth to new entrepreneurs based technology. Through this program, various activities to strengthen the management capacity to do so as technology and innovation to create a climate for growth and development of new businesses based on technological innovation. In practice, given the tenants in the incubator advisory services which include: business planning, market planning, marketing research, business development strategy, new product development, financing strategy, website development and optimization, human resource development, and bookkeeping.

\section{B. Technology Licensing}

Technology licensing is done in the Center for Innovation LIPI has three models are distinguished by the involvement of those who are in the process of licensing. The first model is licensing technology with a previously undergone incubation process technology. Technology incubation is done with the purpose to determine the level of technology readiness before being used by the market.

In this model, the parties involved, namely $\mathrm{R} \& \mathrm{D}$ institutions that produce IP with partners to license. Center for Innovation LIPI as TTO have the duty and function in transferring the technology directly to the partner. The first technology licensing model, the Center for Innovation LIPI has conducted a license to plant breeding technologies which are protected by Plant Variety Protection. Examples of Plant Variety Protection, which has been licensed, is from Aeschynanthus Soedjana Kassan. This plant had originally been through the process of pre-incubation and incubation at Center for Innovation LIPI for two years which aims to make its products meet the desired criteria of the market. Later, the plant is licensed by the cooperative is authorized to reproduce and utilize the invention in accordance with the licensing agreement, including license fees and royalties.

The first model of technology transfer are as follows:

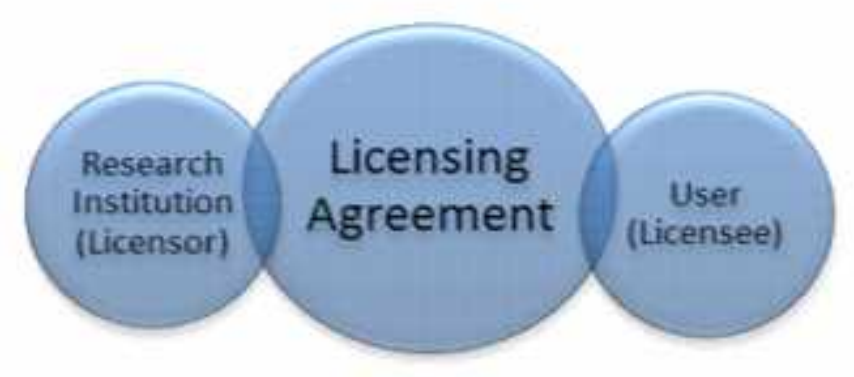

Fig. 2. Technology Licensing in LIPI with Incubation process

The next technology licensing models are licensed technology that involves a third party as an investor. The involvement of investors in these models is not directly related to $\mathrm{R} \& \mathrm{D}$ institutions but as a partner of the partner who will buy the technology. In this model the technology to be licensed not through the incubation process technology, because the technology is ready for commercial assessed and already have a partner (licensee). License Nanoberas technology is one example of successful technology licensed through a model of this technology. The technology is licensed through this model:

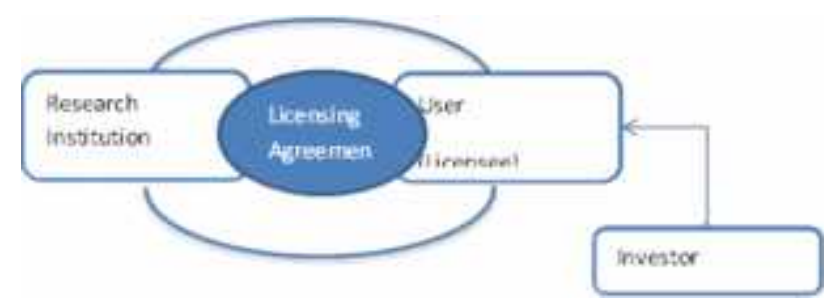

Fig. 3. Technology Licensing in LIPI without Incubation Process I

The latest of technology licensing model is a form of licensing technology that involves three parties, namely the research institutes as licensor, Technology Transfer Office (Center for Innovation) and Industry (user) as a Licensee. In this model of licensing third-party technologies have their respective roles. Research institutions play a role in providing the technology research results have sale value or can be utilized by a wider public. TTO instrumental in making a feasibility study of the technologies produced by research institutions as well as exploring collaboration with industry. While the user as a Licensee is an industry that requires technology generated for research institutions to develop or create new products. A licensing model like this has been done Center for Innovation LIPI in conducting licensing of the technology for rehabilitating degraded land to PT. Ostindo. This third licensing model can be described in the following flow: 


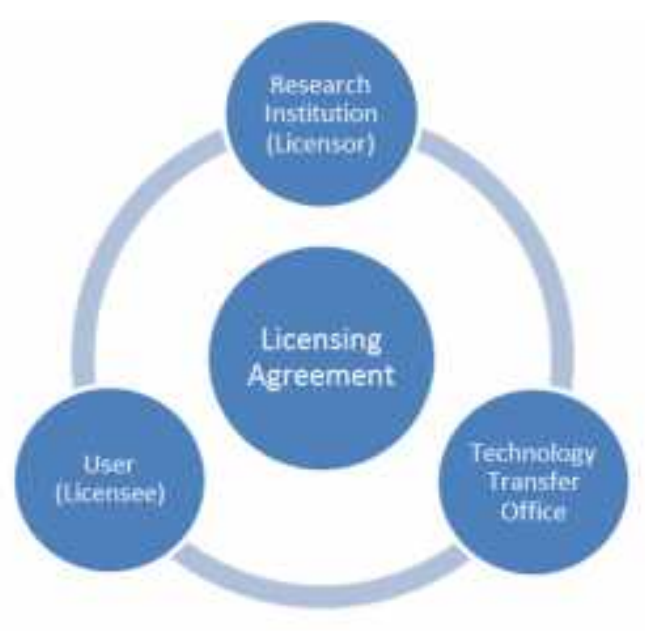

Fig. 4. Technology Licensing in LIPI without Incubation Process II

The success criteria for licensing are less strict than for the start-up, but there are a number of key parameters that must be met. One, patents must be granted or filed patent applications. Two, the benefits of the technology must be demonstrable to potential licensees, either via a prototype or proven customer validation. Three, must offer end-user benefits over competitor offerings or benefits to licensees, Licensing is most successful when the invention of LIPI solution is a good fit with an existing industry need, Licensing can provide access to development resources, markets and a (partial) exit for inventors, established markets and players, and research institutions has to access to proof concepts of funds.

\section{New Company as a Tenant}

While the licensing model may seem to offer lower overall returns than taking an equity stake for research organizations, most IP created does not have the characteristics needed to derive real sustainable competitive advantage in the marketplace and achieve returns required to attract venture capital investment. In addition, the risks and resource requirement associated with licensing of technologies are much lower than in venture start-up and licensing can provide an early and steady cash flow to the organization over a period, rather than waiting for a distant liquidity event of low probability.

Center for Innovation is one of the organizations that experienced many developments LIPI. Similarly, the technology transfer process conducted by the Center for Innovation, a major development occurred when the Center for Innovation incubator have any buildings and workshops in 2013. Until this year there are at least 18 technologies adopted by the discovery of a strategic partner which are start-up companies that became tenants at the Center for Innovation LIPI to get assistance. The formation of tenant or Start-up Company that comes from a company that adopts the technology of LIPI, either through the incubation process or directly into a start-up.

New entrepreneurs or entrepreneurial innovative technology-based or in a more general form as a start-up company is a major component of the economy of a nation. This is partly caused by impacts, such as the creation of new jobs, tax revenue potential and an important actor in adopting technological innovations to produce high value added products. The development of technology-based startup company into one of a raft of the main goals of economic development and science and technology. The existence and role of a start-up company based on technology is becoming increasingly important in the low capacity of local industries that have been established to adopt research results domestic research institutions for risk factors of technical and business are still high so the start-up company will be an industry-based technology in the future front. Increasing the number and quality of Start-up Company can be accelerated through the synergistic role of stakeholders who have an interest and capacity. Technology incubators, as one of the actors, have an important role to be able to develop and move the Indonesian economy by intensifying and commercialize the technology.

In this paper, the definition of a start-up company follows that of the World Intellectual Property Organization (WIPO) where it is defined as a company funded by a venture capital investment with a speculative nature as the investors will be stop investing in a short time frame (3 to 7 years) [26]. The start-up company's patent has been made available by a technology developer, in this case, is LIPI. The investment put into a start-up company is intended to bring up the company's patent to the state where an exit is possible [26].

Given that the start-up company will typically develop new patents as its asset, there is also a negative perception where the start-up company's patent is co-licensed and co-owned by the individual, university, research institute or government laboratory [26]. There is a more positive perception when all the patent is the property, instead of it being in part owned and part licensed. Usually the sides who made the patent available to the start-up company is aiming for their shares, rather than for royalties [26].

In addition to a strong and experienced commercial team, successful commercialization by the start-up pathway requires a strong IP position (i.e. patents filed) in all global markets where the technology is applicable. A technical team with entrepreneurial ambitions that is committed to transferring from the research institution or company to the new venture, broad 'platform' technology with applications in many high growth markets, fits the typical profile of a venture capital investment (i.e. potential to be huge with a likely exit opportunity within a 3 year timeframe), multiple applications for the technology - "platform technology", Nascent market with high growth potential, disruptive Technology, and research institutions has access to investment funding.

\section{CONCLUSION}

Commercialization of the technology derived from the results of the research can be categorized into two, namely through technology licensing and new company formation. Technology to be licensed should have had the protection of intellectual property, either already granted or at the stage of applications filed. Besides the benefits of the technology must be demonstrable to potential licensees, either via a prototype 
or proven customer validation. Licensor also must convince the Licensee regarding the end-user benefits over competitors. Licensing is most successful when the invention of institution (LIPI's) solution is a good fit with an existing industry need.

Another form of commercialization of research findings, namely the establishment of new technology-based companies. The results of the research will be developed through the establishment of new companies should requires a strong IP position in all global markets, where the technology is applicable. New company can also be succeed as a technical team with entrepreneurial ambitions that is committed to transferring from the research institution or company to the new venture.

\section{REFERENCES}

[1] Carlsson B. \& Stankiewicz R. On the Nature, Function And Composition of Technological Systems. Journal of Evolutionary Economics, (1991). 1: 93-118.

[2] Markard J. \& Truffer B. Technological Innovation Systems And The Multi-level Perspective: Towards an Integrated Framework. Research Policy, (2008). 37: 596-615.

[3] Wahab S. A., Rose R. C. \& Osman S. I. W. Defining the concepts of technology and technology transfer: A literature analysis. International Business Research, (2012). 5: 61-71.

[4] Mom T. J. M., Oshri I. \& Volberda H. W. The skills base of technology transfer professionals. Technology Analysis \& Strategic Management, (2012). 24: 871-91.

[5] Kim J., Daim T. U. \& Anderson T. R. University Technology Transfer: A Conceptual Model of Impacting Factors and Phased Process. PICMET '09 - 2009 Portland International Conference on Management of Engineering \& Technology (2798-811).2009.

[6] The Ministry of State Secretariat Government Regulation no. 20 of 2005 concerning Intellectual Property Technology Transfer. Jakarta: The Ministry of State Secretariat:2005.

[7] The Ministry of State Secretariat Indonesian Presidential Regulation Number 27 of 2013 on the development of entrepreneurial incubator. Jakarta: The Ministry of State Secretariat:2013.

[8] Bradley S. R., Hayter C. S. \& Link A. N. Models And Methods of University Technology Transfer. Foundations and Trends ${ }$ in Entrepreneurship, (2013). 9: 571-650.

[9] Siegel D. S., Waldman D. A., Atwater L. E. \& Link A. N. Toward a Model Of The Effective Transfer Of Scientific Knowledge from Academicians to Practitioners: Qualitative Evidence from The Commercialization of University Technologies. Journal of Engineering and Technology Management, (2004). 21: 115-42.
[10] Perkmann M., Tartari V., McKelvey M., Autio E., Broström A., D’Este P., Fini R., Geuna A., Grimaldi R., Hughes A., Krabel S., Kitson M., Llerena P., Lissoni F., Salter A. \& Sobrero M. Academic Engagement and Commercialisation: A Review of The Literature on UniversityIndustry Relations. Research Policy, (2013). 42: 423-42.

[11] Göktepe D. Investigation of University Industry Technology Transfer Cases: A Conceptual and Methodological Approach. Danish Research Unit for Industrial Dynamics. Project at University Lund:2005.

[12] Yamamoto T. Does Technology Transfer From Universities to Industry Contribute to Innovation? In K. Hishida (Ed.), Fulfilling The Promise of Technology Transfer: Fostering Innovation for The Benefit of Society (15-22). Tokyo: Springer Japan:2013.

[13] Presentation material, Olga Spasic, IP Licensing, in National Advance Training on Successful Technology Licensing, Jakarta 9-12 Juny 2015.

[14] Siegel D. S., Waldman D. A., Atwater L. E. \& Link A. N. Commercial Knowledge Transfers from Universities to Firms: Improving The Effectiveness of University-Industry Collaboration. The Journal of High Technology Management Research, (2003). 14: 111-33.

[15] Choi H. J. Technology Transfer Issues and A New Technology Transfer Model. The Journal of Technology Studies (49-57).2009.

[16] Cantamessa M. \& Montagna F. Management of Innovation and Product Development (2016). London: Springer-Verlag.

[17] WIPO Exchanging Value Negotiating Technology Licensing Agreements (wipo pub. 906e). Geneva: World Intellectual Property Organization:2010.

[18] WIPO Successful Technology Licensing (wipo pub 903). Geneva: World Intellectual Property Organization:2015.

[19] Arora A. Patent Protection, Complementary Assets, and Firms' Incentives for Technology Licensing. Management Science, (2006). 52: 293-308.

[20] Aulakh S. P., Jiang S. M. \& Pan Y. International Technology Licensing: Monopoly Rents, Transaction Costs and Exclusive rights. Journal of International Business Studies, (2010). 41: 587-605.

[21] Arrow K. Economic Welfare and The Allocation of Resources for Invention. Universities-National Bureau Committee for Economic Growth of the Social Science Research Council (Eds.), The Rate and Direction of Inventive Activity: Economic and Social Factors (609-626). Princeton, NJ: Princeton University Press:1962.

[22] Fosfuri A. The Licensing Dilemma: Understanding The Determinants of The Rate of Technology Licensing. Strategic Management Journal, (2006). 27: 1141-58.

[23] Australian Centre for Innovation H. P. C. Best Practice Processes for University Research Commercialisations'.2002.

[24] Hamano Y. Commercialization Procedures: Licensing, Spinoffs nd Start-Ups. Geneva: World Intellectual Property Organization:2011.

[25] Risdon P. Understanding The Technology Transfer Process. VITA Distribution Service:1992.

[26] Mendes P. To License A Patent - or, to Assign It: Factors Influencing The Choice. Geneva: World Intelectual Property Organization:2016. 